\title{
HPV Infection, but Not EBV or HHV-8 Infection, Is Associated with Salivary Gland Tumours
}

\author{
Maja Hühns, ${ }^{1}$ Georg Simm, ${ }^{1}$ Andreas Erbersdobler, ${ }^{1}$ and Annette Zimpfer ${ }^{1,2}$ \\ ${ }^{1}$ Institute of Pathology, University of Rostock, Strempelstrasse 14, 18055 Rostock, Germany \\ ${ }^{2}$ Institute of Pathology, University Medical Centre Jena, Ziegelmühlenweg 1, 07743 Jena, Germany \\ Correspondence should be addressed to Maja Hühns; maja.huehns@med.uni-rostock.de
}

Received 1 July 2015; Accepted 21 October 2015

Academic Editor: Monica Cantile

Copyright (c) 2015 Maja Hühns et al. This is an open access article distributed under the Creative Commons Attribution License, which permits unrestricted use, distribution, and reproduction in any medium, provided the original work is properly cited.

\begin{abstract}
Benign and malignant salivary gland tumours are clinically heterogeneous and show different histology. Little is known about the role of human herpes virus 8 (HHV-8), Epstein-Barr virus (EBV), and human papillomavirus (HPV) infection in salivary gland neoplasms. We investigated the presence of the three viruses in formalin-fixed, paraffin-embedded tissue samples in a cohort of 200 different salivary gland tumours. We performed EBV-LMP-1 and HHV-8 and p16 immunohistochemistry, a specific chip based hybridization assay for detection and typing of HPV and a chromogenic in situ hybridization for EBV analysis. Only one case, a polymorphic low-grade carcinoma, showed HHV-8 expression and one lymphoepithelial carcinoma was infected by EBV. In 17 cases (9\%) moderate or strong nuclear and cytoplasmic p16 expression was detected. The HPV type was investigated in all of these cases and additionally in 8 Warthin's tumours. In 19 cases HPV type 16 was detected, mostly in Warthin's tumour, adenoid cystic carcinoma, and adenocarcinoma NOS. We concluded that HHV-8 infection and EBV infection are not associated with salivary gland cancer, but HPV infection may play a role in these tumour entities.
\end{abstract}

\section{Introduction}

Benign and malignant salivary gland tumours belong to rare head and neck tumours. Most cases are benign and only $20 \%$ are malignant [1]. The majority of the diseases arise in the sixth decade and the sex distribution is equal [2]. Salivary gland tumours show a wide range of phenotypic, biological, and clinical heterogeneity [3]. They occur in the major and minor salivary glands, whereof $80 \%$ of major salivary gland tumours are present in the parotid glands, and less than half of these tumours are malignant [3].

In general, several viruses have been demonstrated to be the trigger of neoplastic diseases of the head and neck, like human papillomavirus (HPV) [4] and different human herpes viruses, like human herpes virus-4/Epstein-Barr virus (EBV) [5], cytomegalovirus (CMV) [6], and human herpes virus 8 (HHV-8) [7]. However, the role of viruses in the genesis of salivary gland tumours remains still debatable.

The aim of the present study was to determine the prevalence of different pathogens like HHV-8, EBV, and HPV in a large cohort of salivary gland tumours. The involvement of these three pathogens was analyzed by immunohistochemistry, a specific chip based hybridization assay, or chromogenic in situ hybridization.

\section{Material and Methods}

2.1. Patients. A total of 200 patients with salivary gland tumours were included, diagnosed between 1990 and 2014 (Table 1). Among those there were 93 malignant and 107 benign tumours of different entities (Table 2). The formalinfixed, paraffin embedded specimens were retrieved from the archive of the Institute of Pathology at the University Medicine of Rostock.

The study was performed with internal review board approval and patients' data were anonymized in accordance with German laws concerning safety data.

2.2. Clinical Data. Clinical data were obtained by reviewing the charts of the Clinical Cancer Registry, University of Rostock. These data were anonymized and included sex, age at diagnosis, and stage (Tables 1 and 2). 
TABLE 1: Patient characteristics of salivary gland tumours.

\begin{tabular}{lc}
\hline Clinical characteristics & $n=200$ \\
\hline Median age, years & 59.9 \\
Range & $11-95$ \\
Sex & \\
$\quad$ Male & $107(53.5 \%)$ \\
$\quad$ Female & $93(46.5 \%)$ \\
Tumour location & \\
$\quad$ Parotid gland & $175(87.5 \%)$ \\
$\quad$ Left side & $84(48 \%)$ \\
$\quad$ Right side & $69(39.5 \%)$ \\
Submandibular gland & $14(7 \%)$ \\
$\quad$ Left side & $7(3.5 \%)$ \\
$\quad$ Right side & $7(3.5 \%)$ \\
Minor salivary glands & $11(5.5 \%)$ \\
Stage at presentation (malignant) & \\
I & $36(38.7 \%)$ \\
II & $18(19.4 \%)$ \\
III & $20(21.5 \%)$ \\
IV & $17(18.3 \%)$ \\
No stadium determinable & $2(2.2 \%)$ \\
\hline
\end{tabular}

2.3. Construction of Tissue Microarrays (TMA). For TMA construction, a hematoxylin and eosin (H\&E) stained slide from each block was used to define the representative tumour and normal region by an experienced pathologist. Tissue cylinders with a diameter of $1.0 \mathrm{~mm}$ were punched from the specimen block and brought into an empty paraffin block [8] by using a precision instrument (Beecher Instruments, Silver Spring, MD, USA). Three tissue cylinders of tumour and one cylinder with normal tissue from every specimen were prepared. Taken together, 10 different TMA blocks with malignant and benign specimens were constructed.

2.4. Immunohistochemistry. For each TMA block, four-micrometer sections were transferred to an adhesive-coated glass slide system (Instrumedics Inc, Hackensack, NJ, USA) and stained with H\&E. Only cases containing at least $10 \%$ tumour tissue were further analyzed.

Immunohistochemical staining was performed with an autostainer (EnVision FLEX, High pH, (Link), DAKO, Hamburg, Germany) according to the manufacturer's standard protocol with primary antibodies against Cytokeratin AE1/ AE3 (monoclonal mouse, reference number: $\mathrm{C} 1702 \mathrm{C} 01$, titre 1:500, DCS, Hamburg, Germany), EBV-latent membrane protein-1 (LMP-1) (monoclonal mouse, clones CS.1-4, "ready to use," Dako, Hamburg, Germany), HHV-8 (monoclonal mouse, 1:50, reference number 6011336, Leica, Wetzlar, Germany), and p16 (monoclonal mouse, clone G175-405, 1:20, BD Biosciences, Heidelberg, Germany).

Cytokeratin AE1/AE3 immunohistochemistry served as a positive control for the tissue studied and proved the stainability of the archival material.

For LMP1 of EBV the presence of unequivocal membranous and cytoplasmatic staining in $>2 \%$ of tumour cells was considered positive. For HHV- 8 the presence of nuclear immunoreactivity in $>2 \%$ of tumour cells was considered positive. Positivity for p16 was considered when a moderate to strong staining was observed in the cytoplasm and in the nucleus. The staining intensities were graded as negative, weak, moderate, and strong by visual inspection by an experienced pathologist. Weak and patchy p16 signalling was judged as negative. For positive controls, (tumour) tissues with known marker expression were carried along. The positive controls were as follows: HHV8: Kaposi sarcoma in an AIDS patient; EBV-LMP-1: tonsil with a known infectious mononucleosis (EBV positive); EBER-CISH: tonsil with a known infectious mononucleosis (EBV positive); P16: carcinoma of the tonsil with a known HPV infection.

In the negative control experiments, the primary antibodies were omitted.

2.5. Detection of $E B V$. Chromogenic in situ hybridization (CISH) staining for EBV encoded RNA (EBER) transcripts was performed on $4 \mu \mathrm{m}$ deparaffinized tissue sections, mounted on adhesive coated glass slides according to manufacturer's instructions (ZytoVision, Bremerhaven, Germany). Slides were digested with pepsin solution for 10 minutes, incubated with biotin-labelled ZytoFast EBV probe for 60 minutes at $55^{\circ} \mathrm{C}$, followed by incubation with AP-streptavidin for 30 minutes at $37^{\circ} \mathrm{C}$, and colouring was performed with $\mathrm{NBT} / \mathrm{BZIP}$ at $37^{\circ} \mathrm{C}$ for maximal 40 minutes. Cells exhibiting nuclear staining were considered positive. Positive and negative controls were included in each run.

2.6. Identification of HPV Types. The cases selected for molecular HPV analysis were all tumours with moderate or strong cytoplasmic and nuclear p16 expression and additionally in 8 Warthin's tumours. Tumour DNA was extracted from formalin-fixed, paraffin embedded sections in 25 salivary gland cancers with the ReliaPrep FFPE gDNA Miniprep system (Promega, Mannheim, Germany) according to manufacturers' instruction. For identification of HPV types the HPV Type 3.5 LCD-Array Kit (Chipron, Berlin, Germany) was used according to manufacturer's instructions. Briefly, two PCR reactions were performed using supplied My11/09 (product size $450 \mathrm{bp}$ ) and "125" (product size $125 \mathrm{bp}$ ) primer mixes and analyzed by agarose gel electrophoresis. Both PCR products were mixed and hybridized on the 3.5 LCD chip slide. The slide was subsequently scanned on the Slide Reader Scanner and evaluated with the Slide Reader Software (Chipron, Berlin, Germany).

\section{Results}

3.1. Patient and Tumour Characteristics. We analyzed 200 patients with malignant or benign salivary gland tumours, diagnosed between 1990 and 2014 (Table 1). The mean age at diagnosis was 58.9 years (range 11-95 years), 107 were male (53.5\%), and 93 were female (46.5\%). Different tumour entities were included, whereas in malignant tumours mainly mucoepidermoid carcinoma (18.3\%), adenoid cystic carcinoma (17.2\%), and adenocarcinoma NOS (10.8\%) occurred. 
TABLE 2: Tumour characteristics of malignant and benign tumours $(n=200)$.

\begin{tabular}{|c|c|c|c|}
\hline & Type of tumour & Number of cases & Frequency in $\%$ \\
\hline \multirow{18}{*}{ Malignant } & Mucoepidermoid carcinoma & 17 & 18.3 \\
\hline & Adenoid cystic carcinoma & 16 & 17.2 \\
\hline & Adenocarcinoma NOS & 10 & 10.8 \\
\hline & Salivary duct carcinoma & 9 & 9.7 \\
\hline & Acinus cell carcinoma & 7 & 7.5 \\
\hline & Adenoid basal-cell carcinoma & 5 & 5.4 \\
\hline & Squamous cell carcinoma & 5 & 5.4 \\
\hline & Nonkeratinized squamous cell carcinoma & 4 & 4.3 \\
\hline & Keratinized squamous cell carcinoma & 4 & 4.3 \\
\hline & Oncocytic carcinoma & 2 & 2.2 \\
\hline & Lymphoepithelial carcinoma & 2 & 2.2 \\
\hline & Micropapillary carcinoma & 2 & 2.2 \\
\hline & Myoepithelial carcinoma & 5 & 5.4 \\
\hline & Pseudo sarcomatoid carcinoma & 1 & 1.1 \\
\hline & Polymorphic low-grade carcinoma & 1 & 1.1 \\
\hline & Undifferentiated carcinoma & 1 & 1.1 \\
\hline & Cystadenocarcinoma & 1 & 1.1 \\
\hline & Malignant melanoma & 1 & 1.1 \\
\hline \multirow{7}{*}{ Benign } & Cystadenolymphoma (Warthin's tumour) & 46 & 43 \\
\hline & Pleomorphic adenoma & 33 & 30.8 \\
\hline & Basal-cell adenoma & 15 & 14.0 \\
\hline & Oncocytoma & 7 & 6.5 \\
\hline & Myoepithelioma & 3 & 2.9 \\
\hline & Cystadenoma & 2 & 1.9 \\
\hline & Adenolyphoma & 1 & 0.9 \\
\hline
\end{tabular}

NOS, not otherwise specified.

In benign tumours basically Warthin's tumours (43\%) and pleomorphic adenoma (33\%) were diagnosed.

3.2. Morphological Evaluation of the Specimens. 190/200 (95\%) of the specimens contained $>10 \%$ tumour tissue. Ten cases $(5 \%)$ had limited tumour tissue and were excluded from the study.

\subsection{Expression and Detection of $H H V-8, E B V$, and $H P V$} by Immunohistochemistry. AE1/AE3 positivity was found in $183 / 190(96.3 \%)$ cases, indicating that most tumours were of epithelial origin and were suitable for further investigations (Figure 1(a)).

Only one case, a polymorphic low-grade carcinoma exhibited HHV-8 expression, located in the nucleus (Figure 1(b)).

A small subfraction of only 4 cases expressed the EBVLPM-1 protein and just one case, a lymphoepithelial carcinoma, was positive in EBER-CISH analyses (Figures 1(c) and 1(e)).

Moderate or strong nuclear and cytoplasmic p16 was seen in 17/190 (9\%) cases (Figure $1(\mathrm{~d})$ ). The most frequent tumour type with positive nuclear expression was adenoid cystic carcinoma, followed by adenocarcinoma and acinus cell carcinoma.
3.4. Detection of HPV. Detection of HPV types was performed in all 17 p16 nuclear positive cases and also in 8 Warthin's tumours. In 19/25 cases (76\%) HPV type was classified (Table 3); 6 cases were negative or DNA was not amplifiable. In all 19 positive cases HPV type 16 was detected (Figure 1(f)) in different tumour entities (Table 4 ), mostly in malignant cancer types (12/25) compared to benign tumours (7/25).

\section{Discussion}

The participation of viruses in salivary gland tumours is receiving increasing interest. The role of EBV in lymphoepithelial carcinomas (LEC), nasopharyngeal carcinomas, and also benign Warthin's tumours was reported in several studies $[9,10]$. In our study, we investigated different salivary gland tumours, including 46 Warthin's tumours and two cases of LEC. But EBV was detected only in one LEC (Figures 1(c) and 1(e)). LEC is a rare malignancy and only few cases with EBV infection were described in the literature. It occurs mainly in East Asia population and only rarely in western countries (reviewed in [11]). However, there are many controversies about the association of EBV infection with LEC. Some studies described negative results [12-17], while other authors found a positive association [11, 18-20]. On the basis of our data of only two cases, we are not able 


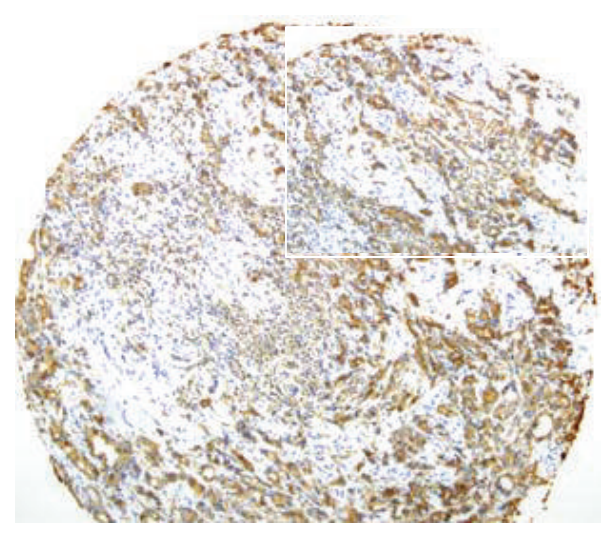

(a)



(c)

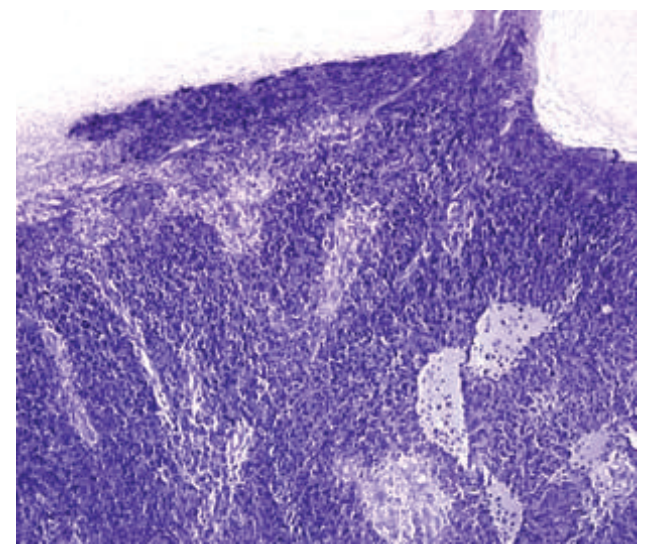

(e)

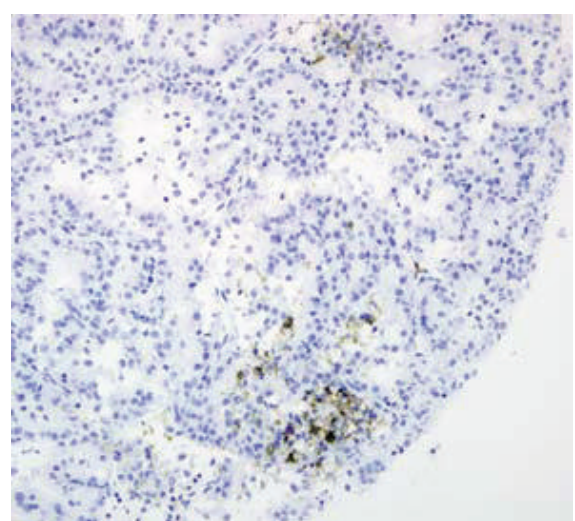

(b)

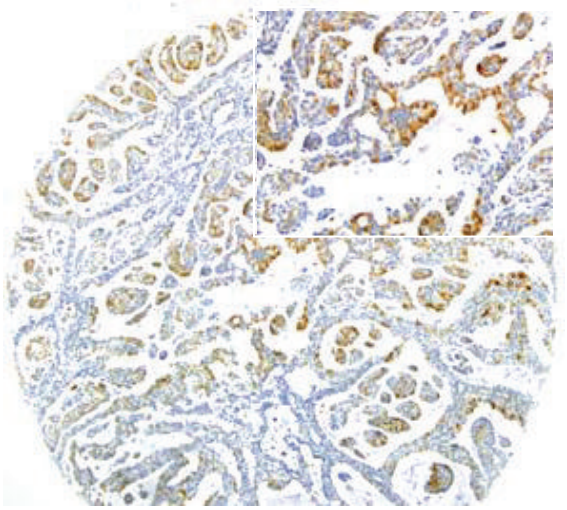

(d)

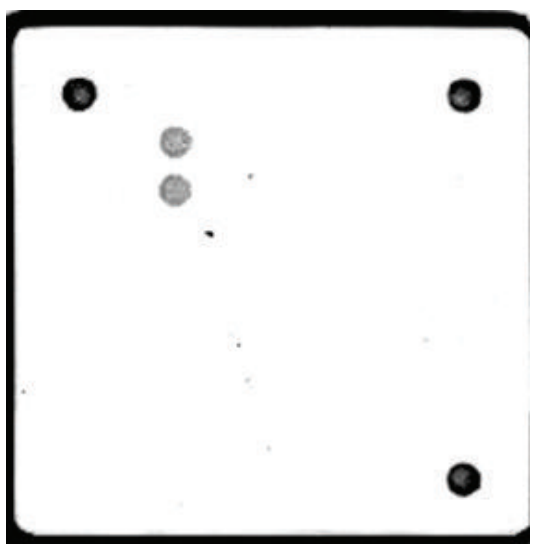

(f)

FIGURE 1: Evidence of pathogens in different salivary gland tumours. (a-d) Immunohistochemistry of (a) AE1/AE3 (10x magnification, in insert 20x magnification) in an adenocarcinoma NOS; (b) HHV-8 (20x magnification) in a polymorphic low-grade carcinoma; (c) EBVLMP-1 (20x magnification) in a lymphoepithelial carcinoma; and (d) p16 expression (10x magnification, in insert 20x magnification) in an adenoid cystic carcinoma. (e) Lymphoepithelial carcinoma showing EBER expression (10x magnification). (f) Adenoid cystic carcinoma with HPV type 16 detected by Chipron LCD array.

to conclude whether EBV is associated with LEC or not. The presence of EBV in Warthin's tumour was described in several studies, with a ratio of about $20 \%[9,21,22]$. However in our study no tumour of this entity showed any positivity for EBV. The present results indicate that infection with EBV does not play a major role in salivary gland neoplasm.
HHV-8, which naturally infects only humans, is known to be involved in various malignancies including Kaposi's sarcoma, Castleman's disease, and primary effusion lymphoma [23-26]. Nevertheless, the role in salivary gland tumours is still unclear. Klussmann et al. reported that HHV-8 has no major tropism to salivary gland epithelium in immunocompetent patients [27]. However, they detected HHV-8 in 
TABLE 3: Expression and detection of HPV, EBV, and HHV-8 in salivary gland tumours by immunohistochemistry, CISH, and chip technology.

\begin{tabular}{lcccccc}
\hline & $n$ & Positive & $\begin{array}{c}\text { Distribution of } \\
\text { malignant cases }\end{array}$ & $\begin{array}{c}\text { Distribution of } \\
\text { benign cases }\end{array}$ & Negative & Not evaluable \\
\hline HHV-8 & 190 & $1(0.5 \%)$ & 1 & 0 & $187(98.4 \%)$ & $2(1.1 \%)$ \\
EBV-LMP-1 & 190 & $4(2.1 \%)$ & 3 & 1 & 0 & $183(96.3 \%)$ \\
EBER-CISH & 190 & $1(0.5 \%)$ & 1 & $3(1.6 \%)$ & $187(98.4 \%)$ & $2(1.1 \%)$ \\
p16 & 190 & $17(9 \%)$ & 14 & 7 & $159(83.5 \%)$ & $1(7.5 \%)$ \\
HPV (chip) & $25^{*}$ & $19(76 \%)$ & 12 & $3(20 \%)$ \\
\hline
\end{tabular}

${ }^{*}$ Cases with strong nuclear p16 positivity and Warthin's tumours; HHV-8, human herpes virus 8; EBV-LMP-1, Epstein-Barr virus latent membrane protein-1; EBER-CISH, Epstein-Barr virus encoded RNA-chromogenic in situ hybridization; p16, cyclin-dependent kinase inhibitor 2A; HPV, human papillomavirus.

TABLE 4: Distribution of HPV type 16 positive cases in salivary gland tumours $(n=19)$.

\begin{tabular}{lc}
\hline & Positive \\
\hline Adenoid cystic carcinoma & 4 \\
Adenocarcinoma NOS & 3 \\
Invasive ductal carcinoma & 1 \\
Acinus cell carcinoma & 2 \\
Adenoid basal-cell carcinoma & 2 \\
Warthin's tumour & 6 \\
Pleomorphic adenocarcinoma & 1 \\
\hline
\end{tabular}

a bilateral MALT-lymphoma of the parotid gland of a HHV-8 seropositive female patient suffering from Sjögren's syndrome [27]. Other reports found out that HHV-8 is uncommon in the saliva of healthy persons but was found in patients with Kaposi's sarcoma $[28,29]$. Klussmann et al. concluded that a latent infection of the salivary gland in people from areas with low prevalence of Kaposi's sarcoma is rare [27]. In contrast, in a Greek study HHV-8 was detected in $44 \%$ of Warthin's tumour [7]. Our findings differ from the Greek study, since we detected no HHV-8 in our 46 investigated Warthin's tumours. Only in one adenocarcinoma NOS the virus was found.

p16 is a cyclin-dependent kinase inhibitor of CDK4 and CDK6, which activates the negative cell cycle regulator retinoblastoma protein $(\mathrm{pRB})$. This protein in turn downregulates p16 expression. The human papillomavirus oncogene E7 interferes with $\mathrm{pRB}$ and inactivates the protein, resulting in overexpression of p16 [30]. Our results showed in 17/190 cases (9\%) a nuclear expression of the surrogate marker p16. Nevertheless, p16 is not a specific marker for the detection of HPV [31] and its value in the detection of HPV infection is still controversial [32]. Due to the role of p16 in cell cycle, we selected only the cases with strong nuclear p16 expression for further HPV typing by DNA analysis. Based on all investigated cases, 19 cases were HPV positive (10\%). In several studies, a correlation of HPV infection, mainly types 16 and 18, with salivary gland tumours was shown. In American patients with mucoepidermoid carcinoma $36 \%$ were positive, predominantly type 16 and less commonly HPV type 18 or types 16 and 18 together [33]. In two other studies similar results were shown for salivary gland tumours. Hafed et al. detected positivity for HPV type 16 and/or type 18 in $23.5 \%$ [34], whereas Lin et al. found $35.8 \%$ positive HPV cases [9]. In contrast, in other studies with Warthin's tumours no HPV-positive case could be found [32, 35]. In our cohort of salivary gland carcinomas we identified 6 Warthin's tumours infected with HPV type 16, after preselection by 16 expression, according to $13.3 \%$ of all investigated Warthin's tumours.

Most positive HPV cases in our study derived from malignant salivary tumours like adenoid cystic carcinoma and adenocarcinoma NOS and, to a lower proportion from acinus cell carcinoma, salivary duct carcinoma and adenoid basal-cell carcinoma. Recent studies also showed conflicting results with malignant tumours. In some studies with up to or more than 100 salivary gland neoplasms, no HPV positive cases were identified [32, 35-37]. In contrast, other studies showed a presence of HPV in these tumour entities [9, 33, 34].

Besides smoking and alcohol consumption, HPV represents another risk factor for squamous head and neck tumours [38]. High-risk (hr) HPV types, often type 16, were frequently detected in oropharynx carcinoma, mainly in tonsillar carcinoma and tongue base carcinoma [38, 39]. Recent advances in HPV-induced cervical precancerous lesions highlight that different pathways of HPV infection (i.e., viral persistent, transient or latent infection, productive or permissive infection) may or may not progress to a "transforming infection," with risk of developing high grade squamous intraepithelial lesion and consecutive invasive cancer [40]. The data show that only a minority of hr HPV infections become "transforming infections," characterised by altered gene expression, especially 2 viral genes E6 and E7 (as discussed above) [40]. Among hr HPV types, type 16 is obviously associated with the greatest risk to develop cervical cancer if left untreated $[40,41]$. But which factors determine malignant progression is still poorly understood [40]. And for hr HPV positive head and neck tumours, especially oropharyngeal cancers, data concerning the development and progression of "transforming" hr HPV infections are still limited [26].

Risk factors, like several sexual partners and oral practices, were similar to those of HPV-associated cervix carcinoma $[42,43]$. In a recent study, the age for oral HPV infection was dated between 14 and 69 years [44] and is consistent with our results of HPV positive cases (between 31 and 72 years). Due to the growing rates of salivary gland tumours and positivity of HPV types 16 and 18, some studies hypothesized that use of the two available HPV vaccines for cervix carcinoma may cause a reduction of salivary gland cancer $[42,44-46]$. 


\section{Conclusion}

Salivary gland neoplasm is an uncommon and heterogeneous disease. These tumours are not generally associated with EBV or HHV-8 infection. In our investigations we found a correlation between p16 nuclear overexpression and highrisk HPV infection in salivary gland neoplasm. HPV type 16 was identified in adenoid cystic carcinoma, adenocarcinoma NOS, and Warthin's tumours and, to a lesser extent, in acinus cell carcinoma, salivary duct carcinoma, and adenoid basalcell carcinoma. HPV seems to be involved in a significant proportion of salivary gland tumours but its exact role is still controversial due to the recent studies.

\section{Conflict of Interests}

The authors declare that there is no conflict of interests regarding the publication of this paper.

\section{References}

[1] V. S. To, J. Y. Chan, R. K. Tsang, and W. I. Wei, "Review of salivary gland neoplasms," ISRN Otolaryngology, vol. 2012, Article ID 872982, 6 pages, 2012.

[2] L. Licitra, C. Grandi, F. J. Prott, J. H. Schornagel, P. Bruzzi, and R. Molinari, "Major and minor salivary glands tumours," Critical Reviews in Oncology/Hematology, vol. 45, no. 2, pp. 215-225, 2003.

[3] D. J. Adelstein, S. A. Koyfman, A. K. El-Naggar, and E. Y. Hanna, "Biology and management of salivary gland cancers," Seminars in Radiation Oncology, vol. 22, no. 3, pp. 245-253, 2012.

[4] J. M. Boland, E. D. McPhail, J. J. García, J. E. Lewis, and D. J. Schembri-Wismayer, "Detection of human papilloma virus and p16 expression in high-grade adenoid cystic carcinoma of the head and neck," Modern Pathology, vol. 25, no. 4, pp. 529-536, 2012.

[5] A. M. Pollock, M. Toner, M. Mcmenamin, J. Walker, and C. I. Timon, "Absence of Epstein-Barr virus encoded RNA and latent membrane protein (LMP1) in salivary gland neoplasms," Journal of Laryngology and Otology, vol. 113, no. 10, pp. 906-908, 1999.

[6] M. Melnick, P. P. Sedghizadeh, C. M. Allen, and T. Jaskoll, "Human cytomegalovirus and mucoepidermoid carcinoma of salivary glands: cell-specific localization of active viral and oncogenic signaling proteins is confirmatory of a causal relationship," Experimental and Molecular Pathology, vol. 92, no. 1, pp. 118-125, 2012.

[7] E. Dalpa, V. Gourvas, S. Baritaki et al., "High prevalence of human herpes virus 8 (HHV-8) in patients with Warthin's tumors of the salivary gland," Journal of Clinical Virology, vol. 42, no. 2, pp. 182-185, 2008.

[8] J. Kononen, L. Bubendorf, A. Kallioniemi et al., "Tissue microarrays for high-throughput molecular profiling of tumor specimens," Nature Medicine, vol. 4, no. 7, pp. 844-847, 1998.

[9] F. C.-F. Lin, P.-L. Chen, T.-Y. Tsao, C.-R. Li, K.-C. Jeng, and S. C.S. Tsai, "Prevalence of human papillomavirus and Epstein-Barr virus in salivary gland diseases," The Journal of International Medical Research, vol. 42, no. 5, pp. 1093-1101, 2014.

[10] A. E. Rytkönen, P. P. Hirvikoski, and T. A. Salo, "Lymphoepithelial carcinoma: two case reports and a systematic review of oral and sinonasal cases," Head and Neck Pathology, vol. 5, no. 4, pp. 327-334, 2011.

[11] T. Terada, "Epstein-Barr virus associated lymphoepithelial carcinoma of the esophagus," International Journal of Clinical and Experimental Medicine, vol. 6, no. 3, pp. 219-226, 2013.

[12] L. A. Cerilli, V. A. Holst, M. S. Brandwein, M. H. Stoler, and S. E. Mills, "Sinonasal undifferentiated carcinoma: immunohistochemical profile and lack of EBV association," The American Journal of Surgical Pathology, vol. 25, no. 2, pp. 156-163, 2001.

[13] F. Dadmanesh, J. L. Peterse, A. Sapino, A. Fonelli, and V. Eusebi, "Lymphoepithelioma-like carcinoma of the breast: lack of evidence of Epstein-Barr virus infection," Histopathology, vol. 38, no. 1, pp. 54-61, 2001.

[14] S. Ferlicot, F. Plantier, L. Rethers, A. D. Bui, and J. Wechsler, "Lymphoepithelioma-like carcinoma of the skin: a report of 3 Epstein-Barr virus (EBV)-negative additional cases. Immunohistochemical study of the stroma reaction," Journal of Cutaneous Pathology, vol. 27, no. 6, pp. 306-311, 2000.

[15] J. Kulka, I. Kovalszky, E. Svastics, M. Berta, and T. Füle, "Lymphoepithelioma-like carcinoma of the breast: not Epstein-Barr virus-, but human papilloma virus-positive," Human Pathology, vol. 39, no. 2, pp. 298-301, 2008.

[16] E. Szekely, "Lymphoepithelioma-like cholangiocarcinoma (LELC) not associated with Epstein-Barr virus," The American Journal of Surgical Pathology, vol. 25, no. 11, pp. 1464-1466, 2001.

[17] J. C. Tardío, E. Cristóbal, F. Burgos, and J. Menárguez, "Absence of EBV genome in lymphoepithelioma-like carcinomas of the larynx," Histopathology, vol. 30, no. 2, pp. 126-128, 1997.

[18] T. Kuo and C. Hsueh, "Lymphoepithelioma-like salivary gland carcinoma in Taiwan: a clinicopathological study of nine cases demonstrating a strong association with Epstein-Barr virus," Histopathology, vol. 31, no. 1, pp. 75-82, 1997.

[19] C.-C. Tsai, C.-L. Chen, and H.-C. Hsu, "Expression of EpsteinBarr virus in carcinomas of major salivary glands: a strong association with lymphoepithelioma-like carcinoma," Human Pathology, vol. 27, no. 3, pp. 258-262, 1996.

[20] L. M. Weiss, L. A. Movahed, A. E. Butler et al., "Analysis of lymphoepithelioma and lymphoepithelioma-like carcinomas for Epstein-Barr viral genomes by in situ hybridization," The American Journal of Surgical Pathology, vol. 13, no. 8, pp. 625631, 1989.

[21] T. Atula, R. Grénman, P. Klemi, and S. Syrjänen, "Human papillomavirus, Epstein-Barr virus, human herpesvirus 8 and human cytomegalovirus involvement in salivary gland tumours," Oral Oncology, vol. 34, no. 5, pp. 391-395, 1998.

[22] M. Santucci, O. Gallo, A. Calzolari, and R. Bondi, "Detection of Epstein-Barr viral genome in tumor cells of Warthin's tumor of parotid gland," American Journal of Clinical Pathology, vol. 100, no. 6, pp. 662-665, 1993.

[23] C. Casper, "The aetiology and management of Castleman disease at 50 years: translating pathophysiology to patient care," British Journal of Haematology, vol. 129, no. 1, pp. 3-17, 2005.

[24] W. Quinibi, O. Al-Furayh, K. Almeshari et al., "Serologic association of human herpesvirus eight with posttransplant Kaposi's sarcoma in Saudi Arabia," Transplantation, vol. 65, no. 4, pp. 583-585, 1998.

[25] R. G. Nador, E. Cesarman, A. Chadburn et al., "Primary effusion lymphoma: a distinct clinicopathologic entity associated with the Kaposi's sarcoma-associated herpes virus," Blood, vol. 88, no. 2, pp. 645-656, 1996. 
[26] T. Rampias, C. Sasaki, P. Weinberger, and A. Psyrri, "E6 and E7 gene silencing and transformed phenotype of human papillomavirus 16-positive oropharyngeal cancer cells," Journal of the National Cancer Institute, vol. 101, no. 6, pp. 412-423, 2009.

[27] J. P. Klussmann, A. Müller, M. Wagner et al., "Human herpesvirus type 8 in salivary gland tumors," Journal of Clinical Virology, vol. 16, no. 3, pp. 239-246, 2000.

[28] D. J. Blackbourn, E. T. Lennette, J. Ambroziak, D. V. Mourich, and J. A. Levy, "Human herpesvirus 8 detection in nasal secretions and saliva," Journal of Infectious Diseases, vol. 177, no. 1, pp. 213-216, 1998.

[29] P. Cattani, M. Capuano, F. Cerimele et al., "Human herpesvirus 8 seroprevalence and evaluation of nonsexual transmission routes by detection of DNA in clinical specimens from human immunodeficiency virus-seronegative patients from central and southern Italy, with and without Kaposi's sarcoma," Journal of Clinical Microbiology, vol. 37, no. 4, pp. 1150-1153, 1999.

[30] M. E. McLaughlin-Drubin, C. P. Crum, and K. Münger, "Human papillomavirus E7 oncoprotein induces KDM6A and KDM6B histone demethylase expression and causes epigenetic reprogramming," Proceedings of the National Academy of Sciences of the United States of America, vol. 108, no. 5, pp. 21302135, 2011.

[31] R. L. Cantley, E. Gabrielli, F. Montebelli, D. Cimbaluk, P. Gattuso, and G. Petruzzelli, "Ancillary studies in determining human papillomavirus status of squamous cell carcinoma of the oropharynx: a review," Pathology Research International, vol. 2011, Article ID 138469, 7 pages, 2011.

[32] A. Skálová, J. Kapírková, P. Andrle, L. Hostička, and T. Vaneček, "Human papillomaviruses are not involved in the etiopathogenesis of salivary gland tumors," Czecho-Slovak Pathology, vol. 49, no. 2, pp. 72-75, 2013.

[33] T. Isayeva, N. Said-Al-Naief, Z. Ren, R. Li, D. Gnepp, and M. Brandwein-Gensler, "Salivary mucoepidermoid carcinoma: demonstration of transcriptionally active human papillomavirus 16/18," Head and Neck Pathology, vol. 7, no. 2, pp. 135148, 2013.

[34] L. Hafed, H. Farag, O. Shaker, and D. El-Rouby, "Is human papilloma virus associated with salivary gland neoplasms? An in situ-hybridization study," Archives of Oral Biology, vol. 57, no. 9, pp. 1194-1199, 2012.

[35] E. Senft, J. Lemound, A. Stucki-Koch, N. Gellrich, H. Kreipe, and K. Hussein, "Expression of cyclin-dependent kinase inhibitor 2A 16, tumour protein 53 and epidermal growth factor receptor in salivary gland carcinomas is not associated with oncogenic virus infection," International Journal of Oral Science, vol. 7, no. 1, pp. 18-22, 2015.

[36] J. A. Bishop, R. Yonescu, D. Batista, A. Yemelyanova, P. K. Ha, and W. H. Westra, "Mucoepidermoid carcinoma does not harbor transcriptionally active high risk human papillomavirus even in the absence of the MAML2 translocation," Head and Neck Pathology, vol. 8, no. 3, pp. 298-302, 2014.

[37] G. Jour, K. West, V. Ghali, D. Shank, G. Ephrem, and B. M. Wenig, "Differential expression of $\mathrm{p} 16^{\mathrm{INK} 4 \mathrm{~A}}$ and cyclin D1 in benign and malignant salivary gland tumors: a study of 44 cases," Head and Neck Pathology, vol. 7, no. 3, pp. 224-231, 2013.

[38] R. Herrero, X. Castellsagué, M. Pawlita et al., "Human papillomavirus and oral cancer: the international agency for research on cancer multicenter study," Journal of the National Cancer Institute, vol. 95, no. 23, pp. 1772-1783, 2003.

[39] J. P. Klussmann, S. J. Weissenborn, U. Wieland et al., "Prevalence, distribution, and viral load of human papillomavirus 16
DNA in tonsillar carcinomas," Cancer, vol. 92, no. 11, pp. 28752884, 2001.

[40] R. D. M. Steenbergen, P. J. F. Snijders, D. A. M. Heideman, and C. J. L. M. Meijer, "Clinical implications of (epi)genetic changes in HPV-induced cervical precancerous lesions," Nature Reviews Cancer, vol. 14, no. 6, pp. 395-405, 2014.

[41] M. Schiffman, S. Boyle, T. Raine-Bennett et al., "The role of human papillomavirus genotyping in cervical cancer screening: a large-scale evaluation of the cobas HPV test," Cancer Epidemiology, Biomarkers \& Prevention, vol. 24, no. 9, pp. 1304-1310, 2015.

[42] G. Campisi and L. Giovannelli, "Controversies surrounding human papilloma virus infection, head \& neck vs oral cancer, implications for prophylaxis and treatment," Head \& Neck Oncology, vol. 1, article 8, 2009.

[43] H. Riechelmann, "Humane papillomaviren bei Kopf-HalsKarzinomen," Laryngo-Rhino-Otologie, no. 89, pp. 43-48, 2010.

[44] E. Daley, V. Dodd, R. DeBate et al., "Prevention of HPV-related oral cancer: assessing dentists' readiness," Public Health, vol.128, no. 3, pp. 231-238, 2014.

[45] M. L. Gillison, A. K. Chaturvedi, and D. R. Lowy, "HPV prophylactic vaccines and the potential prevention of noncervical cancers in both men and women," Cancer, vol. 113, no. 10, pp. 3036-3046, 2008.

[46] A. B. Ryerson, E. S. Peters, S. S. Coughlin et al., "Burden of potentially human papillomavirus-associated cancers of the oropharynx and oral cavity in the US, 1998-2003," Cancer, vol. 113, no. 10, pp. 2901-2909, 2008. 


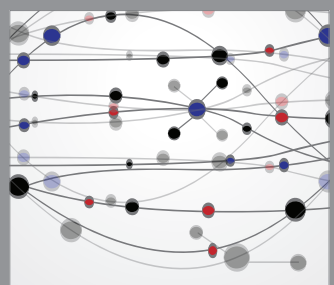

The Scientific World Journal
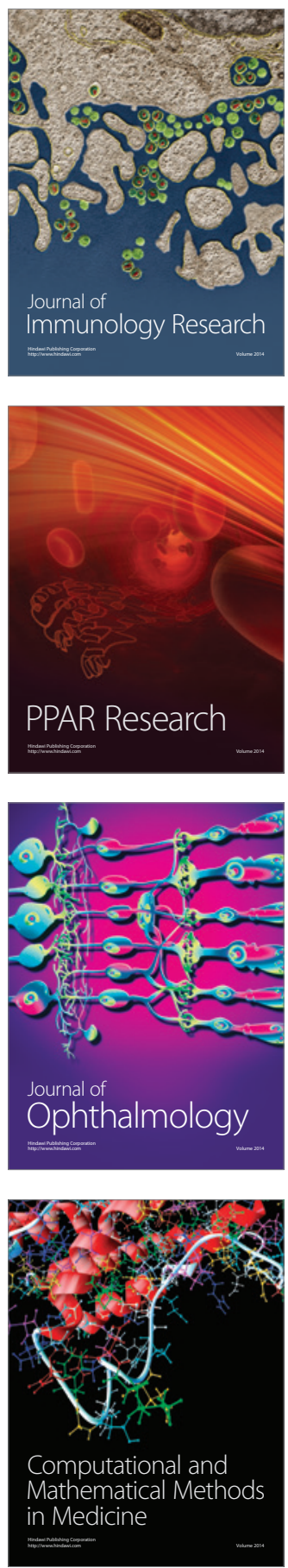

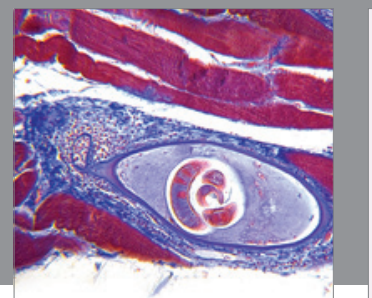

Gastroenterology

Research and Practice
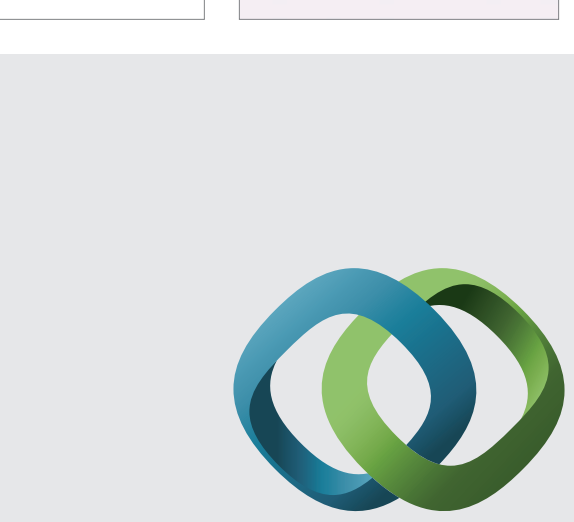

\section{Hindawi}

Submit your manuscripts at

http://www.hindawi.com

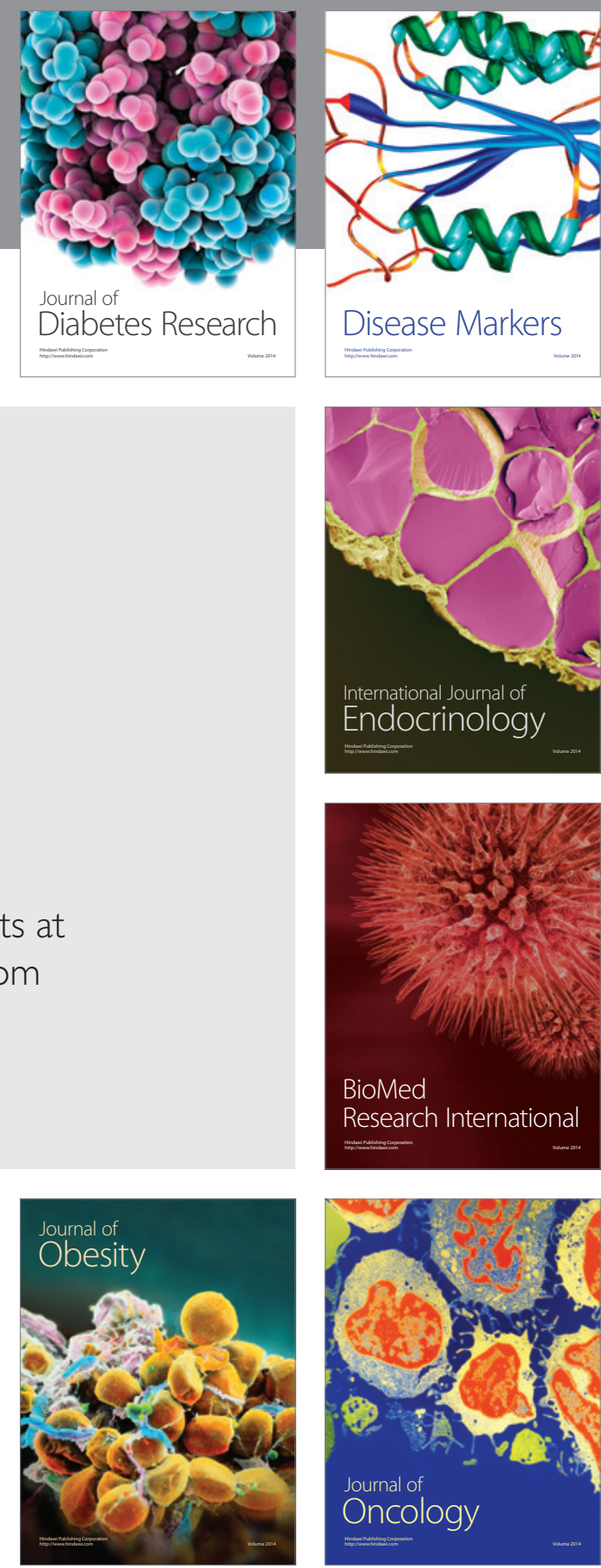

Disease Markers
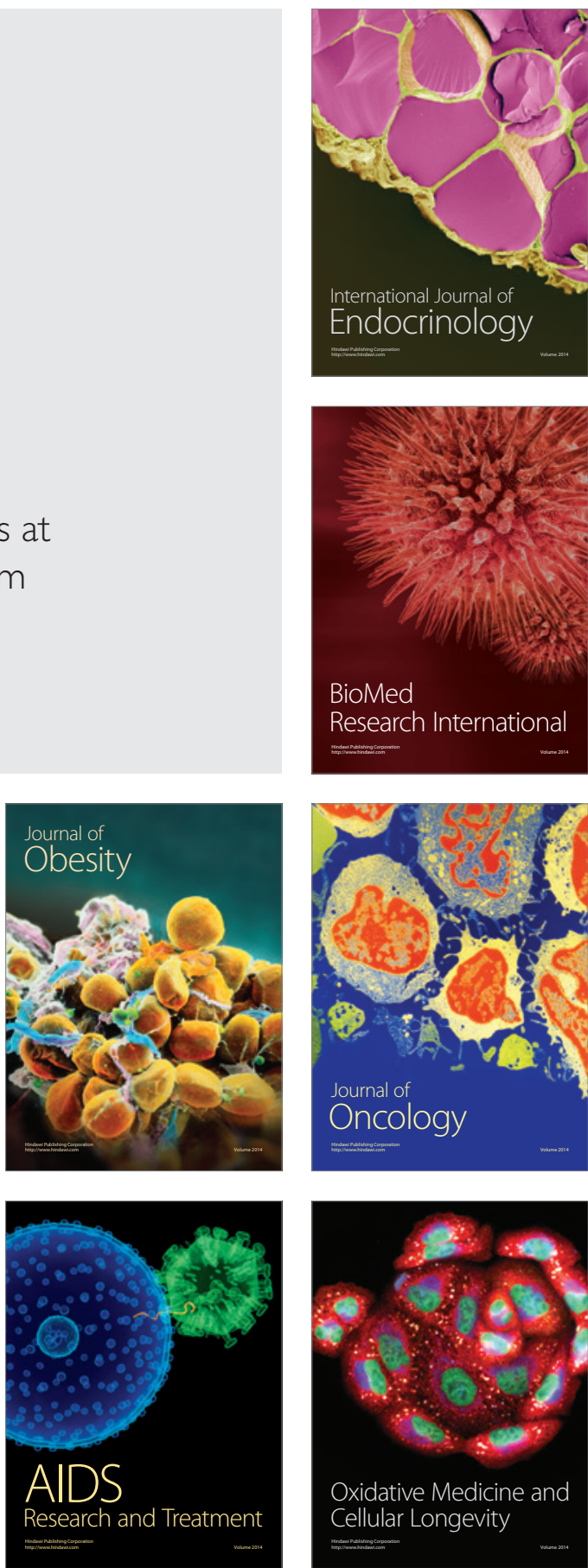